\title{
Novas perspectivas para a classificação
}

\author{
Camila Monteiro de Barros \\ Doutoranda; Universidade Federal de Santa Catarina (UFSC); \\ camibarros2010@gmail.com \\ Renata Padilha \\ Doutoranda; Universidade Federal de Santa Catarina (UFSC); \\ renatapadilha@hotmail.com
}

\begin{abstract}
Resumo: Resenha do artigo The modernity of classification, de Jens-Erik Mai. O tema central do artigo é a discussão das práticas modernas relacionadas à classificação, direcionando a reflexão ao que o autor chama de concepção pósmoderna de classificação. Nessa concepção, ganha espaço a diversidade da experiência humana, sendo, portanto, aceito que qualquer fato pode ter múltiplas interpretações. É nesse sentido que Mai defende que é necessário repensar a base conceitual do trabalho e da teoria de classificação e construir uma fundamentação que comece a partir de uma suposição interpretativa pluralista. A conclusão do artigo baseia-se na possibilidade de adoção da teoria pós-moderna da classificação, devendo-se fazer muito mais do que simplesmente fornecer receitas e métodos de como desenvolver esquemas e sistemas, mas também envolver criticamente a base teórica e a suposição que constitui o trabalho de classificação.
\end{abstract}

Palavras-chave: Teoria da classificação. Sistema de classificação. Semiótica.

A classificação é um tema que permeia processos centrais da Ciência da Informação, especialmente na área da organização do conhecimento (OC). A OC precisa lidar com a complexa relação entre termos e significados e entre conceitos de forma a estabelecer a representação de um domínio de conhecimento (BRÄSCHER; CAFÉ, 2010). Formular essa representação - objetivada nos sistemas de organização do conhecimento (sistemas de classificação, tesauros, etc.) - significa empreender uma série de processos classificatórios em que surgem as relações conceituais. Assim, a classificação precisa ser pensada e repensada de forma que esse processo se mantenha sempre crítico e não simplesmente reprodutivo. 
É com base nesses argumentos iniciais que apresentamos uma resenha do artigo The modernity of classification, cuja proposta é apresentar novas perspectivas para a classificação.

$\mathrm{O}$ autor do artigo The modernity of classification, Jens-Erik Mai, é graduado em Biblioteconomia (1992) e mestre em Ciência da Informação (1994), ambas pela Royal School of Library and Information Science, University of Copenhagen, na Dinamarca. Possui doutorado em Ciência da Informação (2000) pela School of Information, University of Texas em Austin, EUA. Dentre os principais temas de pesquisa destacam-se: Teoria da classificação, Filosofia da Informação, Ciência da Informação, Biblioteca e Ciência da Informação. Atualmente, é professor da Royal School of Library and Information Science, University of Copenhagen, Dinamarca; atua na Association for Information Science and Technology (ASIS\&T) como editor da série de livros Emerald's Library and Information Science; e como membro dos conselhos editoriais de Organização do Conhecimento e Aslib Proceedings.

O tema central do artigo é a discussão das práticas modernas relacionadas à classificação, direcionando a reflexão ao que o autor chama de concepção pósmoderna de classificação. Considerando a classificação uma prática inerente à linguagem humana, o autor constata que os humanos classificam quase que por instinto e sem muito esforço consciente, como uma das formas de interação com o mundo.

Quanto ao trabalho de classificação, como aquele exercido na área da Ciência da Informação (CI) para a criação de sistemas de classificação, este envolve um tipo de flexibilidade interpretativa em que é necessário o esforço de se refletir a respeito do próprio pensamento. Nesse sentido, surge o reconhecimento da distância entre o que é classificado (o objeto) e aquele que classifica (o sujeito), chamada por Mai de distância semiótica.

Em outras palavras, a distância semiótica é o entendimento da condição interpretativa da mente humana, em que qualquer classificação empreendida sobre a realidade é uma classificação artificial, socialmente contextualizada no qual a finalidade tem implicação direta na estruturação da classificação.

Para Mai, a noção atual da atividade de classificação na CI apresenta uma lacuna na explicitação do fundamento ontológico que a origina, deixando 
transparecer uma visão pouco crítica de como, de fato, a classificação de fenômenos é operada. Essa situação faz as noções de classificação natural e nominal se sobreporem, quando na verdade a primeira independe de como a pessoa que classifica vê o objeto, e a segunda se pauta em uma noção do objeto que é criada (por convenção, arbitrariamente, artificialmente, etc.). Dessa forma, uma vaca, por exemplo, é o ser ontológico que é, independente de como a vemos.

Já um sistema de classificação como a CDD ou um determinado termo que tem um significado compartilhado em determinado contexto social se configura como uma forma de expor certo julgamento de valor que não pode ser tomado como único e final. Em uma tentativa de diferenciar categorização de classificação, Jacob (2004) defende que a primeira lida com a questão "sistemática" de entidades, que são artificiais, arbitrárias e esquemáticas e, a outra, se preocupa com as entidades do mundo com base na similaridade entre elas.

Porém, segundo Mai, a categorização e a classificação são totalmente interrelacionadas e interdependentes. Nesse contexto, Mai se preocupa em expor a necessidade de questionar as bases positivistas (neutralidade, matematização, lógica, naturalidade) que ainda permeiam as atividades de classificação na CI.

Na concepção pós-moderna de classificação, ganha espaço a diversidade da experiência humana, sendo, portanto, aceito que qualquer fato pode ter múltiplas interpretações. É nesse sentido que Mai defende que é necessário repensar a base conceitual do trabalho e da teoria de classificação e construir uma fundamentação que comece a partir de uma suposição interpretativa pluralista. Diante disso, o autor destaca três impactos na Ciência da Informação acerca das concepções pósmodernas de classificação: significado dos signos, pluralidade da ordem e proposta de recontextualização.

O primeiro impacto trata da visão do documento como signo, assim, o assunto do documento seria um significado que ocorre em função da semiose do indivíduo. Sendo a semiose um processo de interpretação de um signo, o assunto de um documento não é extraído do documento, mas alcançado na mente de quem executa a interpretação (seja o classificador ou o usuário). Essa perspectiva afasta totalmente a ideia do documento como um contêiner de informação a ser desvendado de forma precisa. 
O segundo impacto visa a crítica à classificação monista que tem como fundamento a unidade do mundo, ou seja, a ideia de que o mundo é organizado segundo uma ordem universal positiva. Com relação a esse aspecto, o autor aborda o pluralismo, incluindo nesta noção as singularidades dos vários contextos sociais, expondo que a classificação deve considerar estas múltiplas perspectivas. Assim, o autor afasta a noção de consenso e defende que a ocorrência de conflitos na categorização de fenômenos pode refletir uma descrição mais real do mundo.

O terceiro impacto complementa a visão pluralista e discute a questão de como a universalização da classificação suprime o contexto local (especificidades). Assim, a classificação descontextualiza os elementos do mundo de forma a serem acomodados na estrutura classificativa em construção, entretanto, há a necessidade destes elementos serem recontextualizados de forma a alcançarem um sentido específico.

A conclusão do artigo baseia-se na possibilidade de adoção da teoria pósmoderna da classificação, devendo-se fazer muito mais do que simplesmente fornecer receitas e métodos de como desenvolver esquemas e sistemas, mas também de como envolver criticamente a base teórica e a suposição que constitui o trabalho de classificação.

A abordagem de Mai se faz muito pertinente neste momento da sociedade em que as tecnologias ampliaram consideravelmente o alcance das classificações, possibilitando inúmeras alternativas de significação da linguagem nos contextos sociais em todo o mundo. Na discussão a respeito dos impactos da visão pósmoderna de classificação, o autor realiza, ainda que timidamente, uma aproximação entre a Semiótica peirceana e a teoria da classificação.

A teoria semiótica de Peirce investiga de maneira profunda a formação do significado individual e do significado compartilhado, além disso, a Semiótica não só aceita como explica logicamente a existência de múltiplas possibilidades significativas para todo e qualquer signo. Para tanto, explora conceitos fundamentais para a área de classificação como interpretação, objeto, referência, significado, signo, entre outros. Essa interdisciplinaridade parece um caminho possivelmente profícuo para uma nova configuração da teoria da classificação na CI.

As teorias ditas tradicionais, como aquelas em que se baseiam a CDD e a 
CDU, por exemplo, repousam na divisão do conhecimento em disciplinas científicas e transportam, portanto, os paradigmas dessas ciências para o sistema de classificação, alocando conceitos, fenômenos e objetos de acordo com as ciências, e não com o contexto social em que tal classificação será aplicada de fato. Além disso, parece recorrente que os princípios teóricos dos sistemas de classificação não sejam registrados, o que torna ainda mais "obscura" a gama de processos utilizados na categorização. A validade do ato de classificar e, por conseguinte, das semelhanças daí advindas e interpostas aos objetos classificados é verificada em relação ao seu propósito e à sua aplicação. Ora, o propósito de uma classificação encontra-se nas ideias que a fundamentam, ou seja, em seus parâmetros teóricos.

Em convergência com a abordagem de Mai, defendemos que o exercício de pensar como e por que a classificação está sendo desenvolvida traz à tona uma posição crítica daquele que realiza o processo de classificação. Assim, a intenção de universalidade classificatória é relativizada, possibilitando que se abram caminhos para explorar o significado do ponto de vista das possibilidades.

\title{
Referências
}

BRÄSCHER, M; CAFÉ, L. Organização da informação ou organização do conhecimento? In: LARA, Marilda L.G.; SMIT, Johanna. (Org.). Temas de pesquisa em Ciência da Informação no Brasil. São Paulo: Escola de Comunicação e Artes/USP, 2010. p. 85-103.

MAI, J. E. The modernity of classification. Journal of Documentation, London, v. 67, n. 4, p. 710-730, 2011.

\section{New perspectives for the classification}

\begin{abstract}
This critical review talks about Jens-Erik Mai's article The modernity of classification. The article discusses modern practices related to classification, upholding mainly to a post-modern conception of classification. Within this conception, the human experience of diversity is centralized, thus, it is accepted that any fact can have multiple interpretations. In this sense, Mai defends that is necessary to rethink conceptual basis of the classification theory and its practices, so it can be developed some grounding that begins with a pluralist interpretative
\end{abstract}


supposition. The article's conclusion is based on the possibility of adopting the postmodern classification theory, indicating that one must make plenty more than just providing methods and recipes about how to develop schemes and systems, as well as also critically involving the theoretical base and suppositions that constitutes the classification practice.

Keywords: Classification theory. Classification system. Semiotics.

Recebido: 12/12/2014

Aceito: $27 / 02 / 2015$ 